\begin{tabular}{|l|l|l|}
\hline & ESCOLA DE \\
PUCRS & HUMANIDADES & $\begin{array}{l}\text { Educação por escrito, Porto Alegre, v. 12, n. 1, p. 1-10, jan.-dez. } 2021 \\
\text { e-ISSN: 2179-8435 }\end{array}$ \\
\hline http://dx.doi.org/10.15448/2179-8435.2021.1.41102 & \\
\hline
\end{tabular}

SEÇÃO: A FORMAÇÃO DE PROFESSORES E A EDUCAÇÃO INCLUSIVA: AVANÇOES, DESAFIOS E PERSPECTIVAS

\title{
Distanciamentos e aproximações da família no ensino remoto
}

\section{Distances and approximations of the family in remote teaching}

\section{Clecimara Vianna ${ }^{1}$}

orcid.org/0000-0002-5299-0873

clecimarav@gmail.com

\section{Silvia Maria de \\ Oliveira Pavão ${ }^{1}$}

orcid.org/0000-0002-5365-0280

silvia.pavao@ufsm.br

\section{Taise Gomes dos}

Santos Cá ${ }^{1}$

orcid.org/0000-0003-1249-5082

taisegomes25@gmail.com

Recebido em: 11/06/2021

Aprovado em: 12/11/2021

Publicado em: 17/12/2021

\section{(c) (1)}

Artigo está licenciado sob forma de uma licença Creative Commons Atribuicãa 4.0 Internacional.
Resumo: As familias assumiram um papel crucial na sistematização do ensino remoto, para alunos com deficiência, durante a pandemia do COVID-19. O objetivo deste artigo foi compreender de que forma as familias de alunos com deficiência efetivam as atividades remotas vinculadas ao Atendimento Educacional Especializado (AEE). Por meio de uma pesquisa qualitativa realizou-se, primeiramente, um estudo sobre aspectos conceituais do ensino remoto. Após, foram traçados os questionamentos, direcionado aos professores de alunos com deficiência, em relação à expectativa e perspectiva do papel da familia no apoio às atividades remotas. As principais constatações obtidas relacionam-se aos dispositivos de acessibilidade utilizados, o conhecimento da realidade dos alunos e professores. Conclui-se que o distanciamento social aproximou as famílias, compreendidas como pais e filhos, na direção de um processo fundamental para o desenvolvimento individual e social.

Palavras-chave: Pandemia. Deficiência. Ensino.

Abstract: Families assumed a crucial role at the systematization of the remote teaching for students with disabilities during the Covid 19 pandemic. The main goal of this article was to comprehend which way disabled student's families carry out remote activities linked to the Specialized Educational Service - AEE. By means of a qualitative research, primarily, a study was made about the conceptual aspects of remote teaching, thereon questions were made, targeted to the disabled student's teachers, regarding the expectation and the perspective of the family's role in supporting remote activities. The main findings obtained relate to the accessibility devices used, the knowledge of the student's and teacher's realities. It is concluded that social distancing approached families, parents with their children, in the direction of a fundamental process for the individual and social development.

Keywords: Pandemic. Disability. Teaching.

Desde que o mundo foi assolado pela pandemia do COVID-19, emergência sanitária ainda em curso, busca-se, de forma contundente, conhecer, compreender e mensurar os impactos desse acontecimento nas áreas do conhecimento e da atuação profissional. Na área da educação, especialmente da educação especial, essa busca se mostra presente, de forma invariável, no cotidiano da pessoa com deficiência, de sua família e do contexto educacional ao qual se vinculam. A fim de minimizar os danos na área educacional provocados pelo distanciamento social, identificado como o melhor procedimento para se evitar o contágio pelo novo coronavirus, algumas alternativas de ensino, utilizando ferramentas digitais, foram colocadas em prática de forma emergencial, destacan- 
do-se, nesse contexto, a adoção da prática de aulas remotas.

Embora o ensino remoto não seja exatamente uma criação do momento atual, no Brasil, a prática dessa modalidade é vista como novidade, suscitando inúmeras dúvidas quanto a sua efetivação. As primeiras associações realizadas na tentativa de compreender o ensino remoto foram realizadas com a educação a distância (aD), modalidade já praticada e legalizada no Brasil. Entretanto, Garcia (2020) destaca que o ensino remoto não significa, necessariamente, educação a distância, mesmo que as duas modalidades utilizem tecnologias digitais. Ensinar remotamente abrange o uso de plataformas abertas, com a possibilidade de compartilhamento de conteúdos acadêmicos nas aulas organizadas em ambientes virtuais de aprendizagem, sendo esses locais administrados por login e senha, como o SIGAA e o MOODLE, ou aplicativos de reuniões, como o Hangouts, ${ }^{2}$ Meet $^{3}$, Zoom ${ }^{4}$ ou as redes sociais.

O Moodle é um Sistema de Gerenciamento de Cursos, originário do inglês Course Management System (CMS) ou Learning Management System (LMS), podendo ser usado em cursos completamente on-line ou servir de complemento para os demais cursos (DALAZUANA, 2014). Já o SIGAA constitui-se como um sistema de informação web corporativo, que informatiza os procedimentos da área acadêmica, por meio dos módulos de graduação, pós-graduação (stricto e lato sensu), ensino técnico, ensino médio e infantil. Essa plataforma também contempla a submissão e controle de projetos na área da pesquisa, extensão, projetos de ensino (monitoria e inovações), além do registro e relatórios de produção acadêmica dos docentes. Possibilita, ainda, criar atividades de ensino a distância em um ambiente virtual de aprendizado denominado Turma Virtual, o qual é o "local" em que todas as informações de uma determinada turma são acessadas e gerenciadas, tendo como o objetivo principal aumentar a interação entre alunos e professores no processo de ensino-aprendizagem (BARROCA FILHO et al., 2013).

O ensino remoto, para Behar (2020), pode ser organizado aliando-se duas formas de trabalho, sendo essas a sincrona, seguindo os principios do ensino presencial, com a utilização de videoaulas e aulas expositivas por sistema de webconferência, junto a atividades assincronas, que seguem durante a semana no espaço de um ambiente virtual de aprendizagem (AVA). No entanto, as dificuldades operacionais e as particularidades dessas mudanças ocorreram repentinamente, sem contar com o apoio de um planejamento adequado (CHIARI, 2012). Sendo assim, alunos com deficiência, imbricados nesse contexto e necessitando de um planejamento com flexibilidade e atenção às suas necessidades especiais, podem ter prejuizos na sua aprendizagem. Nesse panorama, o ensino remoto passou a requerer o apoio crucial das familias. Destaca-se que as familias de pessoas com deficiência vivem, desde o nascimento desses integrantes, uma rotina de cuidados e terapias intensas, sempre de acordo com as necessidades e características de cada pessoa. Porém, não seria correto afirmar que, por essa razão, estariam essas familias aptas a lidarem com o cancelamento abrupto de todos os atendimentos, inclusive o escolar, ocorridos durante a pandemia e, a despeito de todas as mudanças, manterem as atividades escolares em andamento.

Ao se voltar o olhar para o contexto das instituições educacionais, verifica-se o surgimento das ferramentas educacionais, as quais vêm para auxiliar na realização das aulas remotas. Essa modalidade de ensino, de cunho remoto, por sua vez, surge acompanhada de questionamentos direcionados aos docentes, aos alunos e às familias, tais como: As familias estão preparadas para pensar a

\footnotetext{
2 O Hangout é uma plataforma criada pelo Google, que permite a integração e a conectividade de pessoas por meio de mensagens de texto e vídeo, com versões para dispositivos móveis ou fixos, compativeis com os principais sistemas operacionais (BAPTISTA; SOPELETE, 2014).

3 O Google Meet possui um foco corporativo na criação de reuniões gratuitas (SCOLA, 2020).

4 A plataforma de videoconferência possui diversas funções para que os profissionais sejam capazes de ministrar suas aulas (COSTA 2020).
} 
educação nas múltiplas dimensões em que essa se apresenta? Qual o objetivo de tal abordagem? Quais dispositivos de acessibilidade o aluno e a familia possuem? Qual a exata realidade desses alunos - financeira/classe social, relacional? Pessoas menos favorecidas economicamente têm acesso à internet rápida em casa? Possuem conhecimento tecnológico, espaço de estudo, material adequado, familiaridade e conforto para lidar com a tecnologia? Qual o significado do ensino remoto para alunos com deficiência? Em que o ensino remoto pode agregar para o aprendizado do aluno e sua familia? As respostas a essas questões podem ser cruciais para a organização de um modelo de ensino remoto que atenda a todos os alunos, independentemente das deficiências que possuam. Entretanto, ensinar a partir dessa perspectiva engloba, do ponto de vista operacional, uma gama de variáveis, que precisa ser administrada tanto pela instituição educacional quanto pela família.

No que tange a alunos com deficiência, ensinar nesse novo modelo pode impactar na aprendizagem (BRASIL, 2020). As experiências do ensino totalmente online mostram que ele tende a ser mais efetivo para aqueles estudantes que já possuem um desempenho escolar mais alto, gerando riscos de acentuação da elevada desigualdade de aprendizado entre os alunos. Nesse sentido, esse modelo de ensino poderia ocasionar uma disparidade e um aumento das desigualdades sociais e educacionais, ambos já existentes no ambiente escolar. Sob a ótica de distintas perspectivas, podem ser identificados os problemas econômicos ocasionados por esse periodo de instabilidade e as famílias que são as apoiadoras do ensino remoto.

O ensino remoto requer acesso a equipamentos tecnológicos, nível de escolaridade suficiente para que as famílias possam mediar o conhecimento e um ambiente familiar propício ao ensino, dentre outras questões. No Brasil, 67\% dos domicilios possuem acesso à rede, sendo que esse percentual é muito destoante quando dividido entre classes sociais, pois a porcentagem de acesso, de acordo com as camadas sociais, apresenta os seguintes índices: 99\% entre os pertencentes à classe A, 94\% entre os integrantes da classe B, $76 \%$ entre os inseridos na classe $\mathrm{C} \mathrm{e}$ 40\% entre os brasileiros estabelecidos as classes D e E. Os domicilios que, atualmente, não têm acesso à internet, apontam como motivo principal o alto custo (27\%), seguido do fato de os moradores não saberem usar a internet (18\%). Em relação aos dispositivos utilizados para acesso à internet, o telefone celular está presente em 93\% dos domicílios (100\% na classe A e 84\% na classe D e E); computadores, por sua vez, estão em $42 \%$ dos domicilios - sendo $47 \%$ na classe C e $9 \%$ na DE (CENTRO REGIONAL DE ESTUDOS PARA O DESENVOLVIMENTO DA SOCIEDADE DA INFORMAÇÃO, 2019).

No Rio Grande do Sul, a Secretaria de Educação (SEDUC), por meio do Decreto n 55.118 , de 16 de março de 2020 (RIO GRANDE DO SUL, 2020), estabeleceu medidas para a prevenção do contágio pelo COVID-19, além de organizar ações pedagógicas que resultaram na elaboração de atividades curriculares, para que os estudantes mantivessem a carga horária anual de conteúdo. Em vista disso, Costa (2020) aponta que as intervenções, chamadas de aulas programadas, estão acontecendo em plataformas digitais e aplicativos variados. Durante o período de afastamento social, as escolas enviam as atividades via WhatsApp, Facebook, vídeos e e-mails, compartilhando arquivos de áudio. Para aqueles alunos que não têm acesso a nenhum desses meios, a entrega ocorre na escola, de forma presencial. As aulas programadas são atividades previamente estruturadas, baseadas em conhecimentos já abordados em sala de aula, compreendendo um conjunto de aulas a serem cumpridas pelos estudantes e seus respectivos professores, sendo realizadas presencialmente ou não (COSTA, 2020).

Essas novas ações, desenvolvidas na realidade da pandemia, incluem também os alunos que compõem o público-alvo da educação especial (BRASIL, 2008). Diante disso, a Secretaria de Educação do Estado do Rio Grande do Sul (SEDUC), por meio do Departamento Pedagógico, 
lançou para as escolas um documento normativo, referente às orientações para as aulas remotas do modelo hibrido de ensino (RIO GRANDE DO SUL, 2020). Nesse documento, encontram-se as orientações direcionadas aos professores do Serviço de Atendimento Educacional Especializado (SAEE), sendo que a orientação aos professores do Atendimento Educacional Especializado (AEE) está contida do documento intitulado "Orientações para as Aulas Remotas do Modelo Hibrido de Ensino 2020" (RIO GRANDE DO SUL, 2020), o qual insere as familias na condução das atividades pedagógicas. O Atendimento Educacional Especializado (AEE) foi instituido por resolução do Conselho Nacional de Educação (BRASIL, 2009) que, em ato contínuo, normatizou o processo do Atendimento Educacional Especializado (AEE), definindo o público a ser atendido, os recursos e o processo pedagógico básico (BRASIL, 2010, 2010a).

Diante do exposto, o problema de pesquisa se instaurou a partir do seguinte questionamento: como atingir, de forma efetiva, os alunos com deficiência, e como correlacionar o apoio às familias, por meio de ações que respeitem as individualidades e valorizem o trabalho colaborativo no ensino remoto? Sendo assim, o objetivo do estudo foi compreender de que forma as famílias de alunos com deficiência efetivam as atividades remotas vinculadas ao Atendimento Educacional Especializado (AEE). Como objetivos especíicos da pesquisa, elencamos os seguintes: identificar as estratégias e a logística utilizada pela família para a prática do ensino remoto; discutir os processos de mediação das atividades remotas para alunos com deficiência; relacionar o uso das ferramentas virtuais de aprendizagem com as dificuldades encontradas neste processo.

\section{Metodologia}

Para se alcançar os objetivos propostos, priorizou-se a investigação por meio de duas vias, sendo essas a pesquisa bibliográfica do tipo revisão e a pesquisa qualitativa exploratória "[...], com o objetivo de proporcionar uma visão geral, de tipo aproximativo, acerca de determinado fato"
(GIL, 2008, p. 27). Em relação à pesquisa bibliográfica, foram utilizadas referências sobre o ensino remoto e a sua interlocução com o Atendimento Educacional Especializado (AEE) (BRASIL, 2008).

Quanto à técnica de coleta de dados, foram selecionados, por conveniência, o local e os participantes do estudo, sendo esses professores do Atendimento Educacional Especializado (AEE) atuantes em um municipio do estado do Rio Grande do Sul, os quais são educadores especiais pertencentes a uma Coordenadoria Regional de Educação (CRE). Como critério de inclusão, foram selecionados apenas os professores que atenderam, no periodo da pandemia de COVID-19, os alunos com deficiência e as familias desses educandos, sendo requisito terem experienciado as aulas remotas. Foi considerado, para fins de pesquisa, o período de março a setembro do ano de 2020. O instrumento de coleta de dados utilizado foi um questionário semiestruturado, elaborado para esse fim e aplicado por meio virtual, utilizando-se o Google Forms. O questionário foi composto de questões que versavam sobre o perfil dos professores, das famílias e dos alunos pesquisados, além de plataformas, dispositivos e metodologias utilizados, assim como as principais barreiras encontradas. Foram atendidos todos os procedimentos de ética na pesquisa com seres humanos (BRASIL, 2012). Na discussão dos resultados, foi utilizada a abordagem qualitativa. Os participantes, em um total de dez respondentes, foram nomeados sequencialmente, do algarismo um ao dez: Participante 1, Participante 2 e, assim, consecutivamente.

\section{Análise de dados}

O grupo de participantes do estudo foi formado por dez professores, sendo esses educadores especiais que pertencem a uma Coordenadoria Regional de Educação (CRE), a qual engloba sete municípios do estado do Rio Grande do Sul. Questionados em relação à formação inicial, apurou-se que o quantitativo de $60 \%$ dos professores possui cursos de especialização, ao passo que o percentual de $40 \%$ dos respondentes possui o nivel de graduação. Não foram encontrados 
registros de outros niveis de formação, entendendo-se, então, não haver nenhum participante com titulação de mestrado ou doutorado.

Com relação ao tempo de experiência dos profissionais que participaram da pesquisa, constatou-se que 60\% deles trabalham há mais de cinco anos, na rede de ensino, com alunos com deficiência; 30\% dos respondentes trabalham há cinco anos com esse público; $10 \%$ dos participantes possuem experiência de dez anos de trabalho voltado à educação de alunos com deficiência. Desse modo, esses dados denotam que o perfil dos participantes da pesquisa é de professores com formação e experiência no atendimento aos alunos com deficiência.

Quando questionados em relação aos tipos de deficiência que estão sendo atendidas, responderam que, no momento, dos alunos atendidos por eles, 90\% apresentam deficiência intelectual, sendo que, alguns desses, ainda manifestam outras deficiências associadas, tais como: transtorno do espectro autista (TEA), deficiência auditiva e deficiência física e/ou visual. A faixa etária dos alunos atendidos varia de 5 a 18 anos, sendo que a maior parte se encontra na faixa dos 9 aos 12 anos, concentrando-se, portanto, no ensino fundamental.

Quanto às questões referentes ao grupo familiar dos alunos, verificou-se que a renda média das familias está entre R\$768,00 e R\$1.500,00. O percentual de $22,2 \%$ dos estudantes com deficiência possui um irmão(ã) que também é estudante. Esse dado leva à conclusão de que mais de um estudante, da mesma familia, também precisa usar equipamentos, internet e demais recursos necessários para o ensino remoto ser concretizado. O montante de 44,4\% dos estudantes é auxiliado pelo pai ou pela mãe nas atividades, e $11,1 \%$ dos alunos pesquisados recebem auxilio de outro familiar na realização das tarefas escolares. Além disso, 3,3\% dos entrevistados têm outra pessoa na familia que também necessita de auxilio para a realização das atividades escolares, por também ser uma pessoa com deficiência.
Acerca disso, uma das participantes mencionou: Há uma dificuldade muito grande em acessar alunos com deficiência intelectual não alfabetizados. Muitas vezes, há pessoas com dificuldades no mesmo grupo familiar. Estes alunos não acessam plataformas digitais, e quando buscam atividades impressas na escola, acabam não devolvendo. Outra questão é que as salas de AEE no Classroom demoram a serem abertas. Eu mesma nem tenho sala ainda. Único meio de contatar os alunos é através do telefone e material impresso. Poucos tem WhatsApp. Está bem complicado. ${ }^{5}$

No tocante às ferramentas de interação virtual utilizadas entre alunos e professores, verificou-se que os professores estão utilizando variadas plataformas na dinâmica do ensino remoto. A mais empregada é o WhatsApp, seguida pelo Classroom, pelas salas virtuais e pelo Facebook. Isso demonstra que as formas de acesso disponibilizadas pelo governo do estado estão funcionando como meios de disponibilizar conteúdos aos alunos, porém, a troca de mensagens com as familias ainda é o elo mais eficaz. Os educadores que não utilizam plataformas digitais dividem-se entre a utilização de jogos, correspondendo ao percentual de $40 \%$ desses professores, e a disponibilização, na escola, de textos impressos a serem retirados pelas famílias, sendo essa última prática adotada por 50\% do grupo de respondentes. Essas ações demonstram que a acessibilidade também pode ser operacionalizada por meio desses materiais, pois a mesma garante que a prática do ensino siga em voga mesmo em tempos atípicos como o atual.

Quanto aos recursos que cada professor possui, neste momento de ensino remoto, para mediar a aprendizagem, a metade dos professores que participaram do estudo informou que possui, ao menos, um aparelho celular, estando esse dispositivo eletrônico munido de aplicativos que favorecem a acessibilidade. Porém, ainda há a outra parte, de mesmo percentual (50\%), que não possui equipamentos nem materiais adequados a serem utilizados para fins educativos.

Em relação à abordagem mais utilizada pelos educadores, destaca-se o recurso da videoaula,

5 Depoimento da Professora 1 concedido a presente pesquisa, via Google Forms na cidade de Santana do Livramento em 18 de maio de 2020 . 
tanto para as atividades com os alunos quanto para veicular as explicações necessárias para as familias. Nesse tipo de metodologia, o professor reproduz o ambiente da sala de recursos, a fim de garantir as condições para que as familias possam mediar a rotina da sala de aula em ambiente domiciliar. A questão está em identificar as diferentes formas em que a videoaula pode ser utilizada, aproveitando-se ao máximo o seu enfoque. Observou-se que um percentual considerável, representando $80 \%$ dos professores, utiliza o apoio dos vídeos, tanto para tratar com os alunos quanto para trabalhar com as familias dos estudantes. A utilização de vídeos, com a finalidade de servirem como conteúdo de ensino, abordando um assunto determinado, pode ocorrer de duas formas: forma direta, quando informa sobre um tema específico, orientando sua interpretação; forma indireta, quando mostra um tema, permitindo abordagens múltiplas, interdisciplinares (MORAN; MASETTO; BEHRENS, 2000, p. 40). Segundo os educadores especiais, $80 \%$ das familias possuem internet de baixa qualidade para acesso às aulas remotas, demonstrando que a internet ainda é um empecilho para a acessibilidade digital.

Os professores, quando questionados acerca do objetivo do ensino remoto, e sobre como entendem o espaço de diálogo entre a escola e a familia, no contexto da pandemia, responderam, em unanimidade, que as questões curriculares, neste momento, são irrelevantes. Alguns educadores especiais expressaram que a prioridade atual é a formação cidadã dos estudantes, porém, a notável maioria dos professores, em meio à realidade do distanciamento social, considera a aprendizagem de novos conteúdos o elemento primordial, indicando este como o principal objetivo do ensino remoto. Somando-se a isso, "a criança precisa sentir satisfação de executar os trabalhos inerentes a sua vida estudantil porque nesse sentir, certamente, ela estará experimentando o gosto em ser produtiva, competente, útil e responsável" (BRUNO; MOTTA, 2001, p. 113). Na percepção dos professores, as familias, durante o ensino remoto, estão se esforçando para realizar as atividades com os filhos. Esse dado condiz com o aspecto relativo à participação da familia no apoio às atividades de ensino, "pois é neste campo de experiências seguro que [...] aprenderam e comprovarão continuamente que, apesar de suas graves limitações, é-lhes permitido serem eles mesmos" (BUSCAGLIA, 1993, p. 90).

Quando perguntados sobre o conhecimento das famílias dos estudantes, tanto em relação às tecnologias digitais quanto às condições de executarem as orientações pedagógicas repassadas pelos educadores, o percentual de $80 \%$ dos professores atesta que as familias não possuem tais conhecimentos e condições. Sobre esse dado, destaca-se que o domínio das tecnologias informatizadas e as especificidades dos conteúdos escolares demandam tempo para serem aprendidos. Essa constatação está de acordo com o que Kearsley (2012) pontuou, ao defender que certas populações de aprendizes, como crianças, idosos e pessoas com deficiência, têm necessidades especiais em termos de informática. Nesse quesito, uma das participantes explicitou as dificuldades enfrentadas:

No contexto atual, encontro muitas dificuldades.
Trabalho em escolas do campo, com alunos
de baixa renda, os pais têm pouca instrução
e as dificuldades adquirem uma proporção
maior. Eu, como educadora, também me sinto
muito desafiada, porque a interação, em sala
de recursos, sempre foi compreendida, por
mim, como peça fundamental. Tenho alunos
da EJA que são analfabetos, e só posso realizar
atividades através do passo a passo. Não tem
como enviar vídeos explicativos...muito dificil. ${ }^{6}$

Os dados demonstram que nem as famílias, nem os professores, encontram-se preparados para enfrentarem as múltiplas dimensões nas quais se deve pensar a educação baseada no ensino remoto. Quando indagados em relação às barreiras encontradas, 66,7\% dos professores apontam a falta de tempo para prepararem as aulas, ao passo que 55,6\% dos educadores destacam o desinteresse das familias para se

\footnotetext{
6 Depoimento da Professora 2, concedido a presente pesquisa, via Google Forms na cidade de Santana do Livramento em 16 de maio de 2020 .
} 
dedicarem aos estudos dos filhos, configurando-se nesses dois dados os fatores impeditivos mais destacados em relação ao ensino remoto.

A par desse compartilhamento de vivências, existem também dúvidas sobre os efeitos que trabalho realizado exerce em relação à aprendizagem alcançada, tal como referiu a participante $10^{\text {7: }}$

Pra mim, é um pouco angustiante, desde a elaboração, pois não estou realizando a real proposta do $A E E$, estou adaptando materiais impressos para enviar, e com alguns tenho aulas on-line, consigo mantê-los atentos e interessados, por pouco tempo diante do celular!

O ensino remoto, para a expressiva maioria dos educadores especiais participantes do estudo, cobra relevância à medida que esses professores acreditam que essa modalidade de ensino pode servir para criar hábitos de estudos em casa, ocasionando um maior envolvimento da familia na mediação dos conhecimentos. Sobre esse envolvimento, Masetto (2000) considera que o aluno, num processo de aprendizagem, assume o papel de aprendiz ativo e participante (não mais passivo e repetido), de sujeito de ações que o levam aprender e a mudar o seu comportamento. [...].

Acerca dessa questão, a Professora 7 apontou que:

Houve até uma aproximação maior entre o educador e as famílias, visto que o primeiro contato e, na maioria das vezes, os responsáveis pelo aluno são os que recebem, interagem e reenviam as atividades. ${ }^{8}$

Verificou-se, por meio deste estudo, que, na percepção dos educadores, as maiores dificuldades enfrentadas estão concentradas no entendimento das famílias perante as atividades disponibilizadas, tanto sobre o conteúdo quanto à forma de executá-las em casa. A forma de envio da atividade pode configurar um empecilho para a realização da tarefa, já que nem todos possuem acesso à internet. Os professores registraram que $30 \%$ das familias relataram ter dificuldade em entender as atividades, e por isso não as realizaram. Uma parcela das familias se esforçou em realizá-las, porém, não possuiam os materiais e os recursos adequados para executá-las. Outra fração das familias, no entanto, não realizou as atividades porque se sentiram descomprometidas em participar das tarefas escolares, pois entendem que a obrigação de ensinar é da escola. Acerca dessa questão, os professores apontaram que: Existem várias dificuldades de acesso e entendimento. Também é de interesse das familias realizar atividades propostas". 9

Faz-se crucial destacar que Beyer (2005) aponta que não se pode considerar um atendimento pedagógico sem levar em conta as deficiências e as caracteristicas específicas que cada indivíduo apresenta, a fim de que o atendimento pedagógico contemple as especificidades de aprendizagem. Embora haja esforços e boas intenções, alguns alunos não responderão às demandas, pois necessitam de uma pedagogia que os auxilie. Nesse contexto, entende-se que as dificuldades enfrentadas pelas familias vão muito além da acessibilidade virtual, da conectividade ou da aquisição de novos conhecimentos digitais, pois abarcam, além das peculiaridades de aprendizagem que cada estudante apresenta, os recursos necessários para atender a cada deficiência. São especialidades as quais o professor da sala de recursos está preparado para acompanhar e atender, de forma que, por mais que haja esforços para se garantir esse aprendizado, existem habilidades de ensino que pertencem intrinsecamente ao professor da educação especial.

Na percepção dos participantes da pesquisa, constatou-se que a maioria das famílias, mesmo com dificuldades e poucos conhecimentos tecnológicos e/ou educacionais, está conseguindo conduzir as atividades pedagógicas com seus filhos. De acordo com a seguinte entrevistada:

\footnotetext{
7 Depoimento da Professora 10, concedido a presente pesquisa, via Google Forms, na cidade de Santana do Livramento em 19 de maio de 2020 .

8 Depoimento da Professora 7, concedido a presente pesquisa via Google Forms, na cidade de Santana do Livramento em 18 de junho de 2020 .

9 Depoimento da Professora 3, concedido a presente pesquisa, via Google Forms na cidade de Santana do Livramento em 30 de maio de 2020.
} 
A familia sempre foi importante no contexto escolar, uma das participantes afirma que: nesse momento as famílias precisam do nosso apoio e não cobranças. Precisamos estar em contato, orientando, apoiando e transmitindo também conhecimentos. Um momento mais delicado da vida dessas familia. ${ }^{10}$

Além de enfrentar todas as dificuldades relatadas, o professor ainda precisa estar atento aos regramentos da Secretaria de Educação de seu respectivo estado. Os regramentos, na forma de orientações, referentes às aulas remotas no modelo híbrido de ensino, consistem na atenção a várias frentes. Essas frentes se constituem na articulação com a equipe escolar, organização do material adaptado, utilização de tecnologias assistivas, conhecimento das condições do aluno e da família, elaboração de um planejamento individualizado, avaliação da funcionalidade e da aplicabilidade dos recursos pedagógicos e de acessibilidade e, por fim, na orientação às familias, em especial sobre os recursos de acessibilidade que serão utilizados. O educador especial, aliado ao professor da sala regular, deve trilhar um percurso em busca de novos meios, a fim de que o atendimento aos alunos com deficiência alcance um número significativo de famílias, pois, com a pandemia, o grupo familiar será o elo entre a escola e o aluno.

\section{Considerações finais}

A necessidade de se privar do contato social, ocasionada pela atual pandemia, é um fato inédito e inesperado, necessitando o engajamento de toda a comunidade escolar, principalmente das familias de alunos com deficiência. Para esse grupo de estudantes, que notadamente demanda orientações específicas, a importância do papel desempenhado pelo núcleo familiar tornou-se mais visivel, pois a responsabilidade de mediar os conhecimentos e consolidar o aprendizado também foi transformada pelo contexto pandêmico. Se anteriormente à pandemia apenas a figura do educador especial era direcionada ao ensino, de forma biunivoca, esse processo pedagógico, atualmente, transcende essa relação, pois a cooperação e a parceria das famílias tornaram-se imprescindiveis.

Entretanto, concebe-se que as adversidades, e as limitações surgidas no enfrentamento dessas, fazem parte do processo vital. Problemas familiares, destacadamente os de ordem socioeconômico-cultural, são os que mais frequentemente atingem esses alunos. $O$ processo de mediação das atividades remotas, para alunos com deficiência, pode ser dificil, principalmente para as familias com recursos limitados. Dessa forma, a organização, o planejamento e a adaptação podem representar estratégias mais condizentes com a realidade das famílias, para que possam dar o apoio pedagógico, mesmo que com parcos recursos tecnológicos.

Ao se buscar compreender de que forma as famílias de alunos com deficiência efetivam as atividades remotas vinculadas ao Atendimento Educacional Especializado (AEE), concluiu-se que existem inúmeras barreiras no percurso dessa aprendizagem. Porém, a prática do ensino remoto para alunos com deficiência oportunizou algumas benesses, como a estimulação de hábitos de estudos, fortalecimento do acompanhamento, do interesse e do diálogo da família em relação à educação dos filhos. Esses fatores, quando associados, potencializam o desenvolvimento cognitivo e afetivo dos estudantes, delineando um marco positivo em meio às dificuldades trazidas pela pandemia.

Ao se invocar o princípio de equidade, percebe-se que, devido às diferenças sociais e à diversidade dos grupos, o brusco rompimento de uma modalidade presencial, com a repentina mudança para o ensino remoto, impactou o mundo de maneira substancial. No âmago do universo da educação especial, esse impacto deve ser mensurado após serem acrescentadas as múltiplas deficiências, as caracteristicas fenotípicas, as necessidades físicas, demandas de materiais e de acessibilidade que cada aluno com deficiência necessita. Dessa forma, é

10 Depoimento da Professora 8, concedido a presente pesquisa, via Google Forms na cidade de Santana do Livramento em 28 de maio de 2020 . 
latente a concepção de que ainda é preciso compreender e pesquisar acerca do assunto. $\mathrm{O}$ presente estudo é exemplo dessa consciência, pois mesmo se buscando avançar no conhecimento científico, o trabalho apresenta limitações, estando estas relacionadas à amostra, aos dados e à discussão. Como consequência disso, não é possivel estender os resultados obtidos para todo o sistema de ensino da Secretaria Municipal de Educação do Rio Grande do Sul, estando o assunto em aberto para novas pesquisas e novos questionamentos. Maiores indagações e inquietações viriam enriquecer e aprofundar as discussões acerca da triade formada por família, Atendimento Educacional Especializado (AEE) e contexto pandêmico, visto que a realidade recente, representada pelo último elemento, suscitou a necessidade de se repensar e se redescobrir novos caminhos para se lidar com os outros dois pilares da triade, os quais já possuíam bases mais antigas e estabelecidas.

\section{Referências}

BRASIL. Nota Técnica SEESP/GAB/Nº $\mathbf{1 1 / 2 0 1 0}$. Orientações para a institucionalização da Oferta do Atendimento Educacional Especializado - AEE em Salas de Recursos Multifuncionais, implantadas nas escolas regulares. Brasilia: MEC/SEESP/GAB, 2010.

BRASIL. Nota técnica. Ensino a distância na Educação Básica frente à pandemia da Covid-19 Análise e visão do Todos Pela Educação sobre a adoção de estratégias de ensino remoto frente ao cenário de suspensão provisória das aulas presenciais, abr. 2020 [versão para debate e em continua construção]. Disponivel em: https://www.todospelaeducacao.org. br/_uploads/_posts/425.pdf. Acesso em: 12 set. 2020.

BRASIL. Ministério da Educação. Política Nacional de Educação Especial na perspectiva da Educação Inclusiva. Brasilia: MEC/ SEEP; 2008. Disponivel em http:// portal.mec.gov.br/arquivos/pdf/politicaeducespecial. pdf. Acesso em: 23 jun.2020.

BARROCA FILHO, Itamir: AQUINO, Gibeon: SANTA ROSA, José Guilherme. Sigga Mobilie. SIMPÓSIO BRASILEIRO DE INFORMÁTICA NA EDUCAÇÃO, 13.; CONGRESSO BRASILEIRO DE INFORMÁTICA NA EDUCAÇÃO, 2 nov. 2013, Porto Alegre. Anais eletrônicos [...]. Porto Alegre, nov. 2013. p. 92-102. Disponivel em: https://www.br-ie. org/pub/index.php/sbie/article/view/2487. Acesso em: 4 out. 2020. http://dx.doi.org/10.5753/cbie. sbie.2013.92
BAPTISTA, Sara. Rubia. Nunes; SOPOLETE, Monica. Camargo. Hangout: uma alternativa sincrônica e assincrônica para videoconferências e videoaulas. In: SEMINÁRIO NACIONAL DE FORMAÇÃO DE PROFESSORES A DISTÂNCIA: DESAFIOS E PERSPECTIVAS DO CURSO DE PEDAGOGIA, 1., Uberlândia. 2014. Anais [...]. Uberlândia, 2014. Disponivel em: http://next.ensp.fiocruz.br/repositorio/sites/arquivos.next.icict.fiocruz.br/ files/Artigo\%20Hangout\%20-\%20Semin\%C3\%A1rio\%20 EaD\%2oUFU.pdf. Acesso em: 4 out. 2020.

BRUNO, Marilia Moraes Garcia; MOTTA, Maria Glória Batista da. Programa de capacitação de recursos humanos do ensino fundamental. Deficiência Visual. Brasilia: Ministério da Educação, Secretaria da Educação Especial, 2001. v. 3. (Série Atualidades pedagógicas).

BEYER, Hugo Otto. Inclusão e avaliação na escola. Porto Alegre. Mediação, 2005.

BUSCAGLIA, Leo. Os deficientes e seus pais. Rio de Janeiro: Record, 1983.

CENTRO REGIONAL DE ESTUDOS PARA O DESENVOLVIMENTO DA SOCIEDADE DA INFORMAÇÃO-CETIC. TIC domicilios 2019 principais resultados 26 maio 2020. Disponivel em: file:///D:/USER/Downloads/ tic_domicilios_2019_coletiva_imprensa.pdf. Acesso em: 12 set. 2020 .

CHIARI, Aparecida S. Educação a Distância online. Educação Por Escrito, Porto Alegre, v. 2, n. 66-72, 29 fev. 2012

COSTA, Matheus Bigogno. Zoom: aprenda a usar as principais funções para transmitir videoaulas. In: Canaltech. [S. l.], 29 abr. 2020. Disponivel em: https:// canaltech.com.br/apps/zoom-principais-funcoes. Acesso em: 30 abr. 2020.

COSTA, Diego. Aulas Programadas incentivam uso de recursos pedagógicos inovadores na Rede Pública Estadual. In:Secretaria de Educação do Rio Grande do Sul. Porto Alegre, 24 abr. 2020. Disponivel em: https:// educacao.rs.gov.br/aulas-programadas-incentivam-uso-de-recursos-pedagogicos-inovadores-na-rede-publica-estadual. Acesso em: 19 abr. 2020.

DALAZUANA, Jamille Glaucia Barros de Paula. O uso do ambiente virtual de aprendizagem Moodle na formação continuada de professores de Língua Estrangeira. In: DALAZUANA, Jamille Glaucia Barros de Paula. Os Desafios da Escola Pública Paranaense na Perspectiva do Professor PDE: Produção Didático-pedagógica. Curitiba: SEED/PR., 2014. v. 2. (Cadernos PDE). Disponivel em: http://www.diaadiaeducacao. pr.gov.br/portals/cadernospde/pdebusca/producoes_pde/2014/2014_ufpr_lem_pdp_jamille_glaucia_barros_de_paula_dalazuana.pdf. Acesso em: 30 set. 2020

GARCIA, Tania Cristina Meira; MORAIS, lone Rodrigues Diniz; Zaros, Liliam Giotto; RÊGO, Maria do Carmo Diógenes. Ensino remoto emergencial: proposta de design para organização de aulas. Rio Grande do Norte: Secretaria de Educação a Distância, Universidade Federal do Rio Grande do Norte, 2020. (Caderno 1). Disponível em: http://sedis.ufrn.br/wp-content/uploads/2020/06/ ENSINO-REMOTO-EMERGENCIAL_proposta_de_design_organizacao_aulas.pdf. Acesso em: 14 set. 2020. 
GIL. Antonio Carlos. Métodos e técnicas de pesquisa social. 6. ed. São Paulo: Atlas, 2008.

MACEDO, Fausto. Aulas remotas ou EAD/Blog. Estadão, São Paulo, 26 mar. 2020. Disponivel em: https:// politica.estadao.com.br/blogs/fausto-macedo/aulas-remotas-ou-ead/. Acesso em: 22 out. 2020.

MASETTO, Marcos Tarciso. Mediação pedagógica e uso da tecnologia. In: MORAN, José Manuel; MASETTO, Marcos Tarciso; BEHRENS, Maria Aparecida. Novas tecnologias e Mediação Pedagógica. 17. ed. Campinas, SP: Papirus, 2000. p. 163-177.

MESQUITA, Deleni; Piva Jr, DILERMANDO; GERA, Elizabeth Briani Macedo. Ambiente virtual de aprendizagem: conceitos, normas, procedimentos e práticas pedagógicas no ensino a distância 1. ed. São Paulo: Ética, 2014.KEARSLEY Greg. Educação on-line: aprendendo e ensinando. São Paulo: Cengage Learning, 2012.

RIO GRANDE DOS SUL. Secretaria da Educação. Departamento pedagógico. Orientações para as aulas remotas do modelo híbrido de ensino 2020. Porto Alegre, ago. 2020. (slides).

SCOLA, Álvaro. Como criar ou participar de reuniões com o Google Meet. In: Olhar Digital. [S. L.J, 6 maio 2020. Disponivel em: https://olhardigital.com.br/dicas_e_tutoriais/noticia/como-criar-ou-participar-de-reunioes-com-o-google-meet/100362. Acesso em: 4 abr. 2020.

\section{Clecimara Vianna}

Mestre em Políticas Públicas e Gestão Educacional pela Universidade Federal de Santa Maria (UFSM), em Santa Maria, RS, Brasil. Especialização em história do Brasil pela Universidade Federal de Santa Maria (UFSM). Professora da Rede Municipal de Educação de Santa Maria, RS, Brasil.

\section{Silvia Maria de Oliveira Pavão}

Doutora em Educação pela Universidad Autonoma de Barcelona, em Barcelona, Espanha. Mestre em Inovação e Sistema Educativo pela Universidad Autonoma de Barcelona; pós-com doutorado pela Universidade Federal do Rio Grande do Sul (UFRGS), em Porto Alegre, RS, Brasil. Graduada em Educação Especial pela Universidade Federal de Santa Maria (UFSM) em Santa Maria, RS, Brasil. Professora da Universidade Federal de Santa Maria (UFSM), em Santa Maria, RS, Brasil.

\section{Taise Gomes dos Santos Cá}

Mestre em Políticas Públicas e Gestão Educacional pela Universidade Federal de Santa Maria (UFSM), em Santa Maria, RS, Brasil. Tradutora e Intérprete de Lingua de Sinais na Universidade Federal do Pampa, em Santana do Livramento, RS, Brasil.

\section{Endereço para correspondência}

\section{Silvia Maria de Oliveira Pavão}

UFSM CAMPUS SEDE

Av. Roraima, 1000, Prédio 67, sala 1116

Cidade Universitária

Bairro Camobi, 97105-900

Santa Maria, RS, Brasil

Os textos deste artigo foram revisados pela Poá Comunicação e submetidos para validação do(s) autor(es) antes da publicação. 